\title{
Relation between flexor spasms, uninhibited detrusor contractions and anal sphincter activity
}

\author{
EJNER PEDERSEN, * THOR PETERSEN, HENRIK DAA SCHRØDER \\ From the Neurological Laboratory, Aarhus Kommunehospital, Arhus C, Denmark
}

SUMMARY The time relation between flexor spasms, detrusor contractions and anal sphincter activity was recorded in a consecutive series of 111 patients with hyperreflexic bladder and flexor spasms. In 76 of the patients flexor spasms were preceded by detrusor contractions. The opposite pattern, namely detrusor contractions preceded by flexor spasms, was seen in only nine patients. The anal sphincter activity was generally increased in relation to detrusor contractions in patients with spinal lesions but decreased in patients with cerebral lesions. The treatment of flexor spasms and uninhibited detrusor contractions is discussed on the basis of this mutual relationship.

The flexor reflex and associated flexor spasms, which are involuntary contractions in the flexor muscles, ${ }^{12}$ can be increased by lesions of suprasegmental levels in the central nervous system owing to disinhibition. In severe cases flexor withdrawal spasms, often seen in patients with complete upper motor neuron lesions, can facilitate development of contractures. In less pronounced cases flexor spasms may impair mobilisation and can be painful. In this group of patients hyperreflexic bladder is also seen. Hyperreflexic bladder is characterised by uninhibited detrusor contraction at subnormal filling of the bladder resulting in frequency, urgency and urge incontinence. ${ }^{3}$

The striated sphincters are functionally interrelated with the bladder and the lower limb flexor muscles. $^{4-6}$ This paper presents our studies of the mutual relationship between flexor spasms, uninhibited detrusor contractions and activity in the anal sphincter.

\section{Material and methods}

The material was selected from a group of patients with neurological disorder and distinct voiding dysfunction admitted to the Department of Neurology, Aarhus Kommunehospital, Aarhus in the period of 1 January 1981 to 1 December 1983.

The uninhibited detrusor contractions were demonstrated by cystometry using a two-way balloon catheter introduced via the urethra into the bladder. Isotonic saline was infused

Address for reprint requests: Dr T Petersen, Neurological Laboratory, Aarhus Kommunehospital, DK 800 Aarhus, Denmark

*Deceased

Received 4 January 1985 and in final revised form 21 May 1985. Accepted 28 May 1985 at the rate of $20 \mathrm{ml}$ per minute and intravesical and intrarectal pressures were continously recorded. The infusion was stopped during uninhibited contractions to allow isometric conditions. EMG from the anal sphincter was performed by a unipolar needle electrode. Flexor spasms were recorded by their EMG from the tibialis anterior muscle by surface electrodes. The electromyograms were recorded on a multi pen recorder together with the volume of saline infused into the bladder, intravesical pressure, intrarectal pressure and the electronically calculated difference between the two pressures.

One hundred and seventy four patients had detrusor hyperreflexia according to the international criteria based on cystometry, ${ }^{7}$ but 63 of these patients had no flexor spasms and were therefore excluded. The remaining 111 patients, 57 men and 54 women, had a mean age of 56 ranging from 12 to 76 years. Urge incontinence was reported in 103 patients and in eight patients voiding disturbances were reported as urge and/or voiding disability. In two patients voiding disturbances were only a minor part of the illness but in the remaining patients these disturbances were important or predominant. Twenty three patients had cerebral lesions and 18 had spinal lesions as shown in the table. Seventy patients had multiple sclerosis; the disability scores being shown in fig 1 . This rating system has been compared to other systems in a previous report. ${ }^{8}$

\section{Results}

Detrusor contractions preceded flexor spasms in 76 of the 111 patients as illustrated by fig 2 . This order was reproduced at each detrusor hyperreflexia in $63 \%$ of the patients. In 35 of these 76 patients flexor spasms were also recorded without associated detrusor contractions but during bladder contractions these flexor spasms were increased in 12 patients or became synchronous with bladder contractions in the remaining 23 patients.

In four of the 111 patients detrusor contractions 


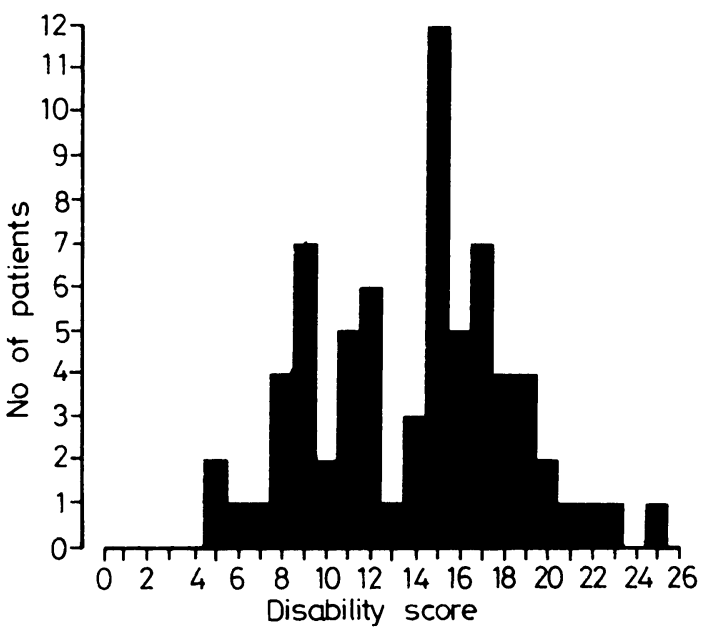

Fig 1 Degree of impairment in 70 patients with multiple sclerosis. 0 represents normal function and 30 maximum impairment.

were followed by relaxation of flexor spasms. Flexor spasms preceded detrusor contractions in nine patients, (fig 3) one of whom also demonstrated detrusor contractions without flexor spasms. In 18 patients no fixed pattern was presented and in the last four patients anal sphincter spasms preceded detrusor contractions and flexor spasms, (fig 4).

EMG activity was unchanged or decreased during uninhibited detrusor contractions in 37 patients as shown in fig 2. Three of these patients also showed relaxation some seconds before the detrusor contractions as illustrated in fig 5. The same figure shows decreased sphincter activity with clonic pattern interspersed throughout the detrusor contractions. All in all this pattern was found in 32 patients.

In 15 of the 18 patients who had lesions only in the
Table The diagnosis in 23 patients with cerebral lesions and 18 patients with spinal lesions

Cerebral Lesions:

Dementia praesenilis

Cerebral thrombosis

Kearn Sayers

Temporal lobe epilepsy

Cerebral arteriosclerosis

Cerebral palsy

Encephalitis acuta sequela

Cerebral aneurysm sequela

Encephalopathia infantilism

Hydrocephalus aquisitus

Contusio cerebri sequela

meningoencephalitis sequela

Grand mal epilepsy

Spinal Lesions:

Myelopathia causa incerta

Cervical osteochondritis

Fracture of the cervical spine

Fracture of the thoracic spine

Fracture of the lumbar spine

Recklinghausen

Ependymoma medulla spinalis

Poliomyelitis sequela

Myelitıs transversalis sequela

spinal cord, sphincter EMG activity was increased throughout detrusor contractions, whereas all 23 patients with cerebral lesions showed relaxation during detrusor contractions. The multiple sclerosis patients contributed to both groups. Further it should be mentioned that in the period of observation five patients without detrusor contractions demonstrated an increase by more than $100 \%$ of flexor spasms during bladder filling.

\section{Discussion}

The present investigation demonstrated that, in the majority of the cases, flexor spasms were preceded by detrusor contractions but the opposite pattern, where flexor spasms were followed by detrusor contractions,

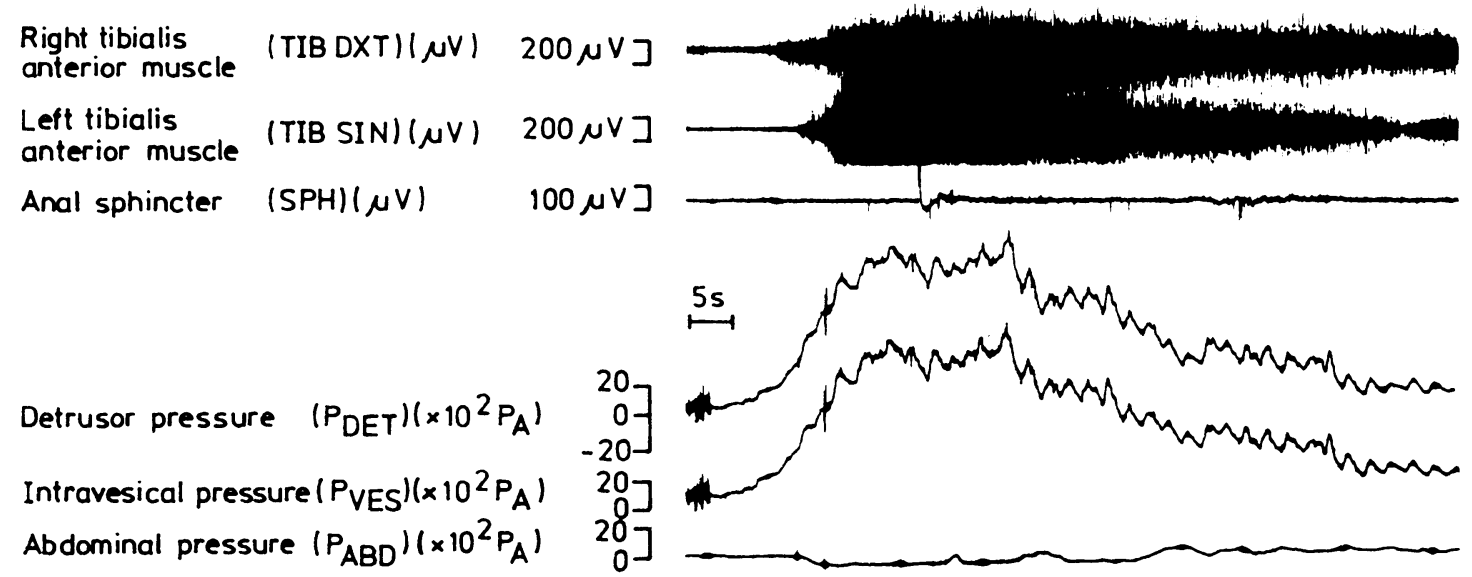

Fig 2 Detrusor contraction preceding flexor spasms. Unchanged sphincter activity during bladder contraction. 


$\begin{array}{ll}\text { TIB DXT } & 200 \mu \mathrm{V}] \\ \text { TIB SIN } & 200 \mu \mathrm{V} J \\ \text { SPH ( } \mu \mathrm{VV}) & 200 \mu \mathrm{V} J\end{array}$

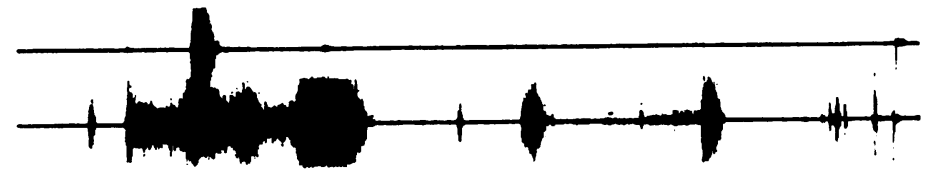

\section{SPH (NV)}

$\stackrel{5 s}{\longmapsto}$
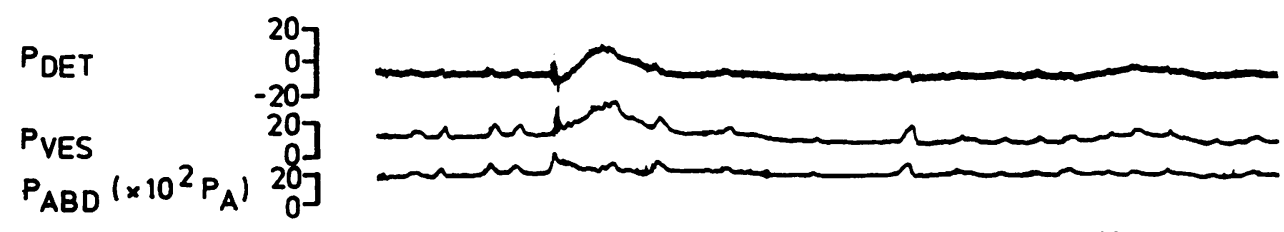

Fig 3 Flexor spasms preceding detrusor contractions. Increased sphincter activity during bladder contraction.

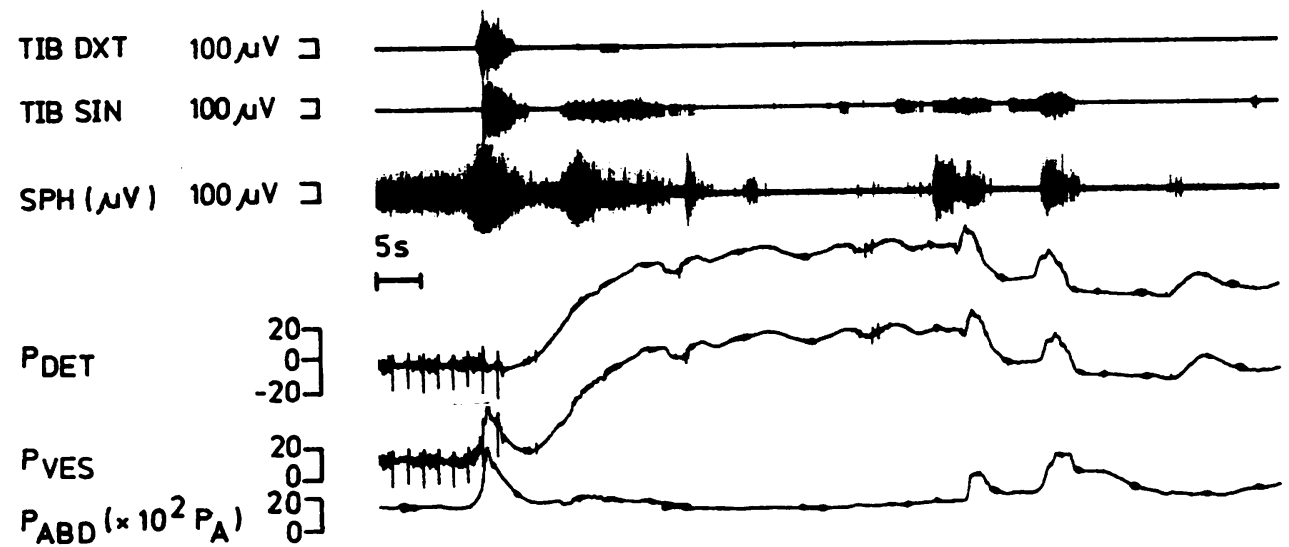

Fig 4 Anal sphincter spasms preceding detrusor contractions and flexor spasms.

TIB DXT $50 \mu \mathrm{V}$

$\begin{array}{ll}\text { TIB SIN } & 50 \mu V \\ & \\ \text { SPH }(\mu V) & 100 \mu V V\end{array}$

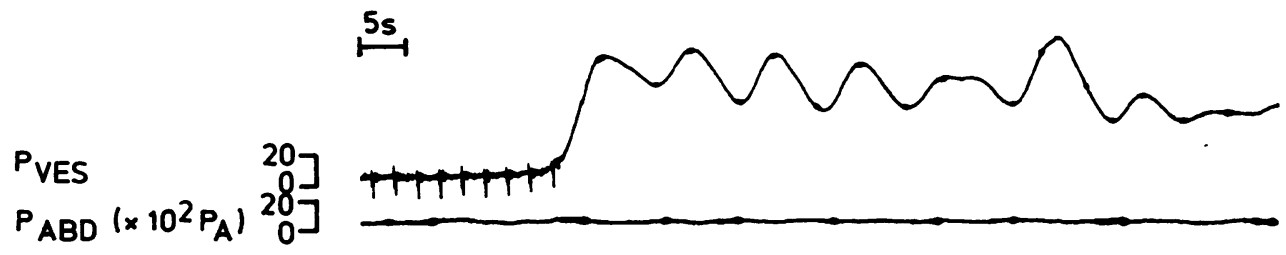

Fig 5 Sphincter relaxation preceding detrusor contraction which again precedes flexor spasms. Clonic pattern of sphincter activity interspersed throughout bladder contraction. 
was seen in some cases. We suppose that a nonspecific excitation from the afferent inflow is taking place in both groups, but different trigger levels decide whether detrusor contractions or flexor spasms are elicited. Afferent inflow from the bladder is thus a potent factor in eliciting flexor spasms.

The patient will often experience a feeling that flexor spasms are being provoked by urge or that incontinence is related to flexor spasms. A patient without bladder sensibility became aware of wetness due to incontinence by the associated flexor spasms. Some patients explained that walking can be impaired when urge is present. However, this connection is not always obvious and may be present even without detrusor hyperreflexia and only during bladder filling. Relaxation of flexor spasms was also seen following detrusor contraction and it is proposed that this is the analog of anal sphincter relaxation during normal voiding. As shown earlier flexor reflex activity during micturition may decrease or increase in a similar manner to activity in the anal sphincter ${ }^{4}$ and reactions on flexor reflex stimulation can be picked up in both sphincters. ${ }^{56}$ Thus there is a connection between the flexor reflex and the striated sphincters but in our study the anal sphincter activity did not always run in parallel to the flexor activity in the leg.

In normal subjects the striated sphincter relaxes when the detrusor contracts in relation to voiding. ${ }^{910}$ This coordination between the smooth and striated muscle can be impaired, and result in detrusor sphincter dyssynergia ${ }^{11}$ showing increased contraction of the sphincter.

In our study an increase of sphincter EMG activity was recorded during uninhibited detrusor contractions in most of the patients with spinal lesions, whereas patients with higher lesions demonstrated decreased sphincter activity sometimes with a clonic activity interspersed throughout detrusor hyperreflexia. This is in accordance with other studies ${ }^{12}$ and supports the theory ${ }^{13}$ that voiding seems to be a longrouted reflex which is integrated at higher levels in the central nervous system than the sacral segments, particularly at pontine levels. The increase of sphincter activity in relation to detrusor contraction is thus a reflection of lesions of the micturition pathway below the pontine level, whereas depression of the sphincter activity is related to lesions at suprapontine levels. In three patients with spinal lesions the theory was not valid but this could be explained by incomplete lesions. $^{14}$

Increased sphincter activity preceding flexor spasms and detrusor hyperreflexia was seen in four patients. This excitatory pathway has been shown to be accentuated in chronic spinal lesions in animals. ${ }^{15}$ However, normal reciprocal bladder inhibition by perineal stimulation is also seen in patients with spi- nal cord injury ${ }^{1617}$ and this knowledge is used either in implanted anal plug pacemakers ${ }^{18}$ or in posterior tibialis nerve stimulation. ${ }^{1920}$ According to our findings we would expect patients with detrusor hyperreflexia preceded by sphincter or flexor spasms to have their voiding symptoms worsened by this treatment. In contrast, patients with relaxation of the anal sphincter or flexor activity in the limbs during detrusor hyperreflexia would be expected to benefit from electrical stimulation. This should particularly be true in patients with a pattern suggesting that the sphincter ceases to function as shown in fig 5 .

However, for the time being treatment in most cases will be medicinal, especially via anticolinergic agents and smooth relaxants. In some patients surgical treatment of the bladder or the nerves to the bladder is of value.

The study was supported by the Danish Multiple Sclerosis Society. We thank Mrs Lis Oades for the help in preparing this article.

\section{References}

${ }^{1}$ Shahani BT, Young RR. Human flexor reflexes. J Neurolo $\bar{\omega}$ Neurosurg Psychiatry 1971;34:616-27.

${ }^{2}$ Shahani BT, Young RR. Human flexor spasms in New Developments. In: Electromyography and Clinical Neurophysiology. Desmedt JE, ed.: S Karger, Basel, 1973;3:734-43.

${ }^{3}$ Petersen T, Pedersen E. Neurodynamic evaluation of voiding dysfunction in multiple sclerosis. Acta Neurot Scand 1984;69:402-11.

${ }^{4}$ Mai J, Pedersen E. Central effect of bladder filling and voiding. J Neurol Neurosurg Psychiatry 1976;39:171-7.

${ }^{5}$ Pedersen E, Harving H, Klemar B, Tørring J. Human anal reflexes. $J$ Neurol Neurosurg Psychiatry 1978;41:813-8.

${ }^{6}$ Jolesz FA, Xu Cheng-Tao, Ruenzel PW, Henneman E. Flexor reflex control of the external sphincter of the urethra in paraplegia. Science 1982;216:1243-5.

${ }^{7}$ International Continence Society Committee on Standardisation of Terminology on Lower Urinary Tract Function, Fourth Report: Neuromuscular dysfunction. Urology 1981;17:618-20.

${ }^{8}$ Grynderup V. A comparison of some rating systems in multiple sclerosis. Acta Neurol Scand 1969;45:611-22.

${ }^{9}$ Bors E, Estin Comarr A. In: Mayor P, ed. Neurological Urology. Basel, S Karger, 1971:31-34.

${ }^{10}$ Barrington FJF. The component reflexes of micturition in the cat. Part III. Brain 1941;64:239-43.

${ }^{11}$ Scott FB, Quesada EM, Cardus D. The use of combined uroflowmetry, cystometry and electromyography in evaluation of neurogenic bladder dysfunction. In: Neurogenic Bladder. Boyarsky S, ed.: Baltimore: Williams and Wilkins, 1967:106-14.

${ }^{12}$ Blaivas JG. The neurophysiology of micturition: A clinical study of 550 patients. $J$ Urol 1982;127:958-63.

${ }^{13}$ deGroat WC, Ryall RW. Reflexes to sacral parasym- 
pathetic neurones concerned with micturition in the cat. J Physiol (Lond) 1969;200:87-108.

${ }^{14}$ Siroky MB, Krane RJ. Neurologic aspects of detrusorsphincter dyssynergia, with reference to the guarding reflex. $J$ Urol 1982;127:953-7.

${ }^{15}$ deGroat WC. Inhibition and excitation of sacral parasympathetic neurons by visceral and cutaneous stimuli in the cat. Brain Res 1971;33:499-503.

${ }^{16}$ Rossier A, Bors E. Detrusor responses to perianal and rectal stimulation in patients with spinal cord injuries. Urol Int 1964;18:181-90.
${ }^{17}$ Vereecken RL, van Mulders J. Das J. Influence of anal sphincter stimulation on bladder contractility. Proc Int Continence Soc 1982:266-7.

${ }^{18}$ Merrill DC. The treatment of detrusor incontinence by electrical stimulation. J Urol 1979;122:515-7.

${ }^{19} \mathrm{McQuire} \mathrm{EJ}$, et al. Treatment of motor and sensory detrusor instability by electrical stimulation. $J$ Urol 1983;129:78-9.

${ }^{20} \mathrm{Khan} \mathrm{Z}$, et al. Use of acupuncture in bladder instability. Proc Int Continence Soc 1982:139-41. 